\title{
CORRECTION OF LEG LENGTH DISCREPANCY BY EPIPHYSIAL ARREST
}

\author{
M. B. Menelaus, Melbourne, Australia
}

From the Orthopaedic Department, Royal Children's Hospital, Melbourne

For the correction of leg length discrepancy by epiphysial arrest, skeletal age rather than chronological age is best used to assess the right time for operation (Green and Anderson 1951, 1957, 1960; Anderson, Green and Messner 1963).

At the Royal Children's Hospital we have previously used a calculation based on chronological age and an assumption of a constant rate of growth at the lower femoral and

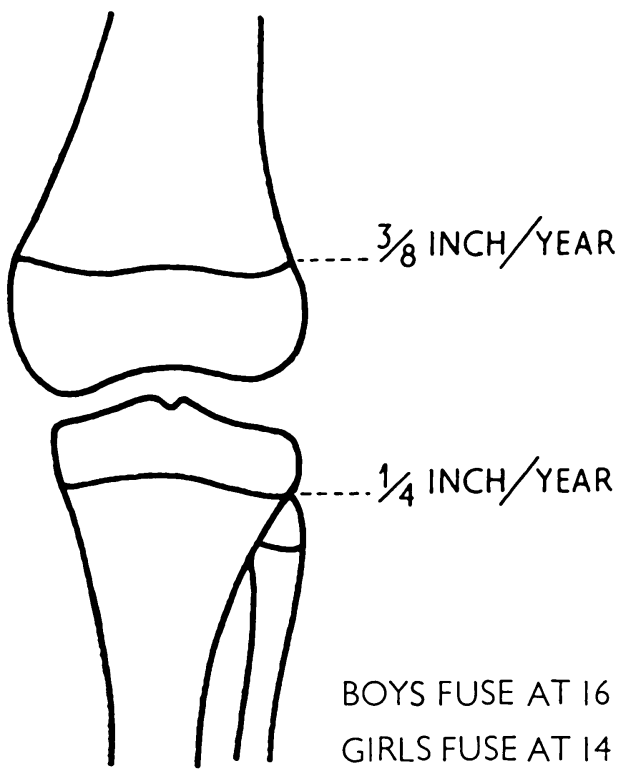

FIG. 1

Showing the assumed rates of growth and the age of cessation in the lower femoral epiphysis and upper tibial epiphysis in boys and girls. upper tibial epiphyses. A knowledge of the annual rate of increase in the discrepancy in leg length before operation is easily included in the calculation. An analysis of fifty-three cases of epiphysial arrest based on this method of calculation suggests that it is more accurate than some methods, and very nearly as accurate as calculations based on skeletal age. It may be of use as a simple calculation which can be done by mental arithmetic, to confirm or modify the timing of epiphysial arrest calculated on skeletal age, or it may be used as an alternative method. It seems useful to have more than one method of calculation; the method considered below has the advantage of simplicity.

The calculation we have used includes the suggestion of White and Stubbins (1944) that the lower femoral epiphysis provides three-eighths of an inch, and the upper tibial epiphysis one-quarter of an inch of growth a year. His original calculations showed that growth stopped at the age of seventeen in boys and sixteen in girls, and later he modified this to sixteen for boys and fifteen for girls. We have assumed growth to stop at the age of sixteen in boys and fourteen in girls. The relevant figures are shown in Figure 1. These approximations we know are not strictly true, as there is not a constant rate of growth or age of cessation. The following is an example of the calculation we have used.

Girl age-11 years Discrepancy- $1 \frac{1}{2}$ inches Therefore expected discrepancy at maturity Fusion of both epiphyses .

$$
\begin{array}{r}
\text { Annual increase }-\frac{1}{8} \text { inch } \\
\begin{array}{r}
1 \frac{1}{2}+\left(\frac{1}{8} \times 3\right)=17 \\
3 \times\left(\frac{3}{8}+\frac{1}{4}\right)=1 \\
3
\end{array} \text { inches }
\end{array}
$$

\section{MATERIAL}

Since 1954 ninety-six children have had their epiphyses arrested, the timing for operation being based upon this calculation. Forty-four of these children are now grown up and are available for study. Fifty-three epiphyses have been arrested in these forty-four children (Table I), the effects of poliomyelitis being the most common condition for which it was done (Table II). 


\section{OPERATION}

Phemister's operation, with minor modifications, was used. The epiphysis was exposed through oblique incisions on the medial and lateral aspects. A rectangle of cortex was removed, one-third of the piece consisting of epiphysis and two-thirds of diaphysis. Through this window as much as possible of the white epiphysial line was gouged out. The rectangle of bone was then punched back into place in the reversed position. The upper fibular epiphysis was gouged out through the incision that exposed the lateral aspect of the tibial epiphysis.

A plaster cylinder was applied for six weeks and the child allowed to walk in this twelve days after operation.

TABLE I

Site of Operation IN FifTY-THREE EPIPHYSES OF FORTY-FOUR CHILDREN

(Twenty-one boys, twenty-three girls)

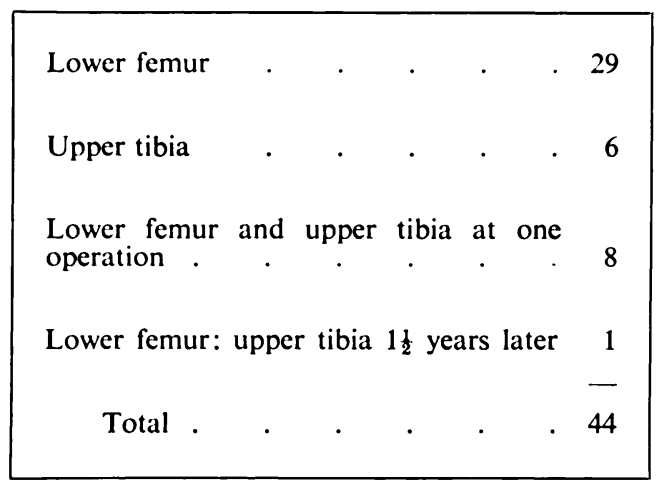

TABLE II

CONDITIONS FOR WHICH OPERATION WAS DONE

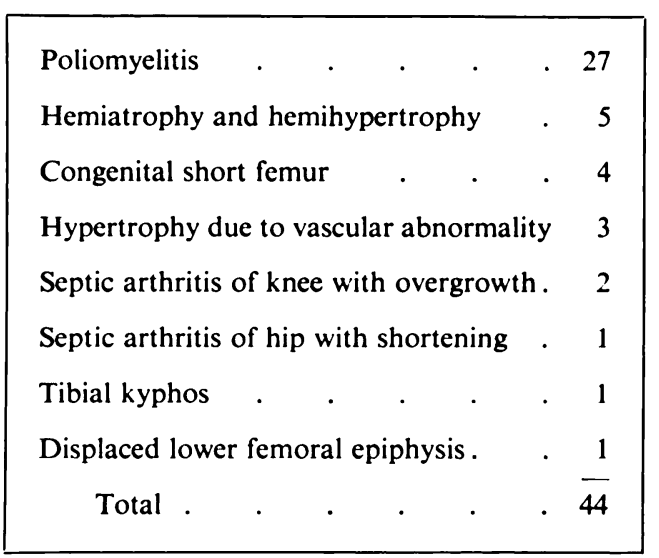

\section{RESULTS}

At maturity 52 per cent of the patients had leg length discrepancy within a quarter inch of the calculated amount, 41 per cent within three-quarters of an inch and 7 per cent had more than three-quarters of an inch error (Table III). In this, and in Table IV, we consider the error between the actual and calculated discrepancy at maturity. A child with, for example, threequarters of an inch difference between actual and calculated discrepancy does not necessarily have three-quarters of an inch length discrepancy at maturity. This is because we have not always aimed at equal leg length for reasons which will be mentioned later. The actual leg length discrepancies at maturity in the three children with more than three-quarters of an inch error were five-eighths of an inch, half an inch and equality of leg length. Much more correction than had been anticipated was achieved; means of overcoming this error will be discussed below.

Stamp and Lansche (1960) performed epiphysial arrests by the same technique for a very similar assortment of conditions, but a different calculation was employed. They anticipated the patient's mature height by measuring the parents', grandparents' and siblings' height. Fifty per cent of growth was assumed to occur in the legs- 40 per cent of this at the lower end of the femur and 30 per cent at the upper end of the tibia. The results (Table III) indicate that this method is not as accurate as that which we have employed.

Comparison of our results with the much larger series of Green and Anderson (1957) is less flattering but more informative (Table IV). Green and Anderson produced graphs showing the growth to be expected from each epiphysis at various skeletal ages and predicted the effect of epiphysial arrest from these curves. Whereas 89.6 per cent of their 125 cases were within one-half inch of the calculated discrepancy at maturity, only 80 per cent of the present series were as accurate. Green and Anderson dealt only with poliomyelitis, and if our small 
series of poliomyelitis children alone is considered, 85 per cent were within one-half inch of the calculated discrepancy. However, the two series are not strictly comparable as they performed epiphysial arrest on the originally short leg for threatened over-correction in 4 per cent of their cases.

Of those children with more than half an inch of difference between actual and calculated discrepancy most had excessive rather than insufficient slowing of growth from operation (16 per cent against 4 per cent).

Excessive slowing of growth has been due chiefly to the difficulty of prediction of the discrepancy at maturity in younger children with considerable shortening. Three of the four

TABLE III

Final Leg Length Discrepancy Compared with Calculated Discrepancy

\begin{tabular}{|c|c|c|c|c|}
\hline & \multicolumn{2}{|c|}{ Present series } & \multicolumn{2}{|c|}{ Stamp and Lansche (1960) } \\
\hline & Number & Per cent & Number & Per cent \\
\hline Within $\downarrow$ inch of calculated discrepancy & 23 & 52 & 29 & 28 \\
\hline Within $\frac{3}{4}$ inch & 18 & 41 & 32 & 31 \\
\hline More than $\frac{3}{4}$ inch error & 3 & 7 & 41 & 41 \\
\hline
\end{tabular}

TABLE IV

Error Between Actual and Calculated Discrepancy at Maturity

\begin{tabular}{|l|c|c|c|}
\hline & $\begin{array}{c}\text { Green and } \\
\text { Anderson (1957) }\end{array}$ & $\begin{array}{c}\text { Present } \\
\text { series }\end{array}$ & $\begin{array}{c}\text { Present } \\
\text { series }\end{array}$ \\
\cline { 1 - 3 } & $\begin{array}{c}\text { (Poliomyelitis } \\
\text { only) }\end{array}$ & (All cases) & $\begin{array}{c}\text { (Poliomyelitis } \\
\text { only) }\end{array}$ \\
\cline { 1 - 3 } & Per cent & Per cent & Per cent \\
\hline Within $\frac{1}{2}$ inch of calculated discrepancy & $89 \cdot 6$ & 80 & 85 \\
Correction more than $\frac{1}{2}$ inch above prediction & 4 & 16 & - \\
Correction more than $\frac{1}{2}$ inch below prediction & 6.4 & 4 & - \\
\hline
\end{tabular}

children in the series who underwent operation under the age of ten years were closer to equality of leg length at maturity than the calculation had suggested. In these circumstances growth should generally be arrested at one epiphysis at an early age and then at the other later. This makes error less likely if, because of change in the rate of growth, the original prediction proves to be inaccurate. We are now doing this more often than was done in the series considered here and this is increasing our accuracy.

\section{COMPLICATIONS}

One child, who had lower femoral arrest, developed varus deformity. This was noted fifteen months after operation; it required re-exploration and repeat fusion of the lateral aspect of the epiphysis. The leg was straight at maturity in every child. No other secondary operative measures were necessary. In two children the originally long leg was one-eighth of an inch short at maturity.

The operation scars were frequently broad and unsightly. For the lower femur an oblique incision running slightly posteriorly as it passes downwards gives the least scarring. For the upper tibia the incision should run slightly forwards and downwards. 


\section{DISCUSSION}

In children with leg length discrepancy we do not invariably aim at leg length equality. Most children who have had a long-standing leg length discrepancy are most comfortable if they are left with a small discrepancy. Children with a flail limb, fixed equinus or abductor weakness of the hip are usually better served by shortness of half an inch on the affected side. If foot stabilisation involving shortening is planned for a later stage then the quarter-inch reduction in length in this limb should be allowed for.

In this series two inches was the average expected discrepancy at maturity if operation was not performed, and the procedure was reserved for children in whom the expected discrepancy at maturity was not greater than three and a half inches. It was felt that the smallness of stature would be unacceptable if greater discrepancies were treated by epiphysial arrest. In borderline cases with uncertainty as to whether this method of correction should or should not be performed, the expected height at maturity was calculated.

Whatever method of calculation is employed, good results depend on accurate records. These should be kept on a standard chart included in the history of all children with leg length discrepancy. Measurements should be recorded at regular six-monthly intervals. We have recorded lengths in inches as this suited our method of calculation. Measurements from the anterior superior iliac spine to the medial malleolus and to the heel should be recorded. More important is to record the discrepancy using blocks, as when the levels of both anterior superior and posterior superior iliac spines are compared, this is the most accurate method. Furthermore, blocks enable one to determine the comfortable raise and hence the desirable discrepancy at maturity.

If careful judgement is used in children with considerable discrepancy and detailed records are kept, the method of calculation considered above is accurate and has the advantage of simplicity.

\section{SUMMARY}

1. A simple calculation for the timing of epiphysial arrest to correct leg length discrepancy is described. An assumption is made that growth ceases at a constant chronological age of sixteen years in boys and fourteen years in girls. It is further assumed that the lower femoral epiphysis provides three-eighths of an inch and the upper tibial epiphysis one-quarter inch of growth each year.

2. Whilst the assumptions made are known to be approximations, analysis of the results of fifty-three epiphysial arrests in forty-four children shows that the errors cancel themselves sufficiently to make this method accurate. The simplicity of the calculation makes it useful to confirm or modify the timing of arrests calculated on the basis of skeletal age, or as an alternative method.

\section{REFERENCES}

Anderson, M., Green, W. T., and Messner, M. B. (1963): Growth and Predictions of Growth in the Lower Extremities. Journal of Bone and Joint Surgery, 45-A, 1.

Green, W. T., and Anderson, M. (1951): Discrepancy in Length of the Lower Extremities. The American Academy of Orthopaedic Surgeons, Instructional Course Lectures, 8, 294.

Green, W. T., and ANderson, M. (1957): Epiphyseal Arrest for the Correction of Discrepancies in Length of the Lower Extremities. Journal of Bone and Joint Surgery, 39-A, 853.

Green, W. T., and Anderson, M. (1960): Skeletal Age and the Control of Bone Growth. The American Academy of Orthopaedic Surgeons, Instructional Course Lectures, 17, 199.

Stamp, W. G., and Lansche, W. E. (1960): Treatment of Discrepancy in Leg Length. Southern Medical Journal, 53, 764.

White, J. W., and Stubiss, S. G., Jun. (1944): Growth Arrest for Equalizing Leg Lengths. Journal of the American Medical Association, 126, 1146.

vOL. 48 B, NO. 2, MAY 1966 